\title{
"Nash-in-Nash" Bargaining: A Microfoundation for Applied Work
}

\section{Allan Collard-Wexler}

Duke University and National Bureau of Economic Research

\section{Gautam Gowrisankaran}

University of Arizona, HEC Montreal, and National Bureau of Economic Research

\section{Robin S. Lee}

Harvard University and National Bureau of Economic Research

\begin{abstract}
A "Nash equilibrium in Nash bargains" has become a workhorse bargaining model in applied analyses of bilateral oligopoly. This paper proposes a noncooperative foundation for "Nash-in-Nash" bargaining that extends Rubinstein's alternating offers model to multiple upstream and downstream firms. We provide conditions on firms' marginal contributions under which there exists, for sufficiently short time between offers, an equilibrium with agreement among all firms at prices arbitrarily close to Nash-in-Nash prices, that is, each pair's Nash bargaining solution given agreement by all other pairs. Conditioning on equilibria without delayed agreement, limiting prices are unique. Unconditionally, they are unique under stronger assumptions.
\end{abstract}

This paper was previously circulated under the title "Bargaining in Bilateral Oligopoly: An Alternating Offers Representation of the 'Nash-in-Nash' Solution." We would like to thank Elliot Lipnowski, Sebastián Fleitas, and Eli Liebman for excellent research assistance; Attila Ambrus, John Asker, Catherine de Fontenay, Joshua Gans, Patrick Greenlee, Heski Bar-Isaac, Rachel Kranton, Volcker Nocke, Janine Miklos-Thal, Dan O'Brien, Alexander Raskovich, Stan Reynolds, Mike Riordan, Chris Snyder, Mike Whinston, Tom Wiseman, Ali Yurukoglu, and numerous seminar audiences for useful discussion; and the editor and three anonymous referees for helpful comments. Gowrisankaran acknowledges funding from the National Science Foundation (grant SES-1425063). The usual disclaimer applies.

Electronically published January 4, 2019

[ Journal of Political Economy, 2019, vol. 127, no. 1]

(c) 2019 by The University of Chicago. All rights reserved. 0022-3808/2019/12701-0004\$10.00 


\section{Introduction}

Bilateral bargaining between pairs of agents is pervasive in many economic environments. Manufacturers bargain with retailers over wholesale prices, and firms negotiate with unions over wages paid to workers. As an example, in 2015, private insurers in the United States paid hospitals $\$ 403$ billion and physicians and clinics $\$ 272$ billion for their services. ${ }^{1}$ Private prices for medical services are determined neither by perfect competition nor by take-itor-leave-it offers (as is assumed in Bertrand competition). Instead, they are predominantly determined by bilateral negotiations between medical providers and insurers.

A substantial theoretical literature has sought to understand the equilibrium outcomes of bilateral bargaining in a variety of settings, including buyer-seller networks (e.g., Kranton and Minehart 2001; Corominas-Bosch 2004; Manea 2011) and wage negotiations (e.g., Jun 1989; Stole and Zwiebel 1996). To derive meaningful predictions, many of these papers have focused on environments in which a single agent is involved in all bargains or in which a transaction between two agents does not affect the value of trade for others. Concurrently, an applied literature-both empirical and theoretical - has focused on surplus division within bilateral oligopoly environments with the goal of evaluating a range of industrial organization questions, including the welfare impact of horizontal mergers (Chipty and Snyder 1999), bundling (Crawford and Yurukoglu 2012), and vertical integration (Crawford et al. 2018) in cable television; the effects of price discrimination for medical devices (Grennan 2013); and the price impact of hospital mergers (Gowrisankaran, Nevo, and Town 2015) and health insurance competition (Ho and Lee 2017). Increasingly, this applied literature is influencing antitrust and regulatory policy. ${ }^{2}$ The applied literature has emphasized interdependencies and externalities across firms and agreements because they are often fundamental to bilateral oligopoly environments. ${ }^{3}$

${ }^{1}$ See exhibit 1 on p. 4 of "National Health Expenditure Accounts: Methodology Paper, 2015" at https://www.cms.gov/Research-Statistics-Data-and-Systems/Statistics-Trends-and -Reports/NationalHealthExpendData/Downloads/DSM-15.pdf.

${ }^{2}$ The Federal Communications Commission used a bargaining model similar to that analyzed in this paper in its analysis of the Comcast-NBC merger (Rogerson 2014) and in recent hospital merger cases (Farrell et al. 2011). Also, in a recent ruling in a restraint of trade case in sports broadcasting, Judge Shira Scheindlin's opinion heavily referenced the Crawford and Yurukoglu (2012) bargaining framework as an appropriate way to consider competition in this sector (Thomas Laumann v. National Hockey League [J. Scheindlin, S.D.N.Y. 2015 12-cv1817 Doc. 431]).

${ }^{3}$ For instance, negotiations between insurers and hospitals are typically interdependent; i.e., an insurer's value from having one hospital in its network depends on the other hospitals that are already in its network. Thus, hospital mergers may raise prices in a bargaining context because the loss to an insurance company from removing multiple hospitals is worse than the sum of the losses from removing individual hospitals (Capps, Dranove, and Satterthwaite 2003). A bargaining model that did not allow for such interdependencies would typically rule out a price increase following a merger. 
To tractably and feasibly analyze the division of surplus in bilateral oligopoly settings with interdependent payoffs, the applied literature has leveraged the relatively simple solution concept proposed by Horn and Wolinsky (1988a) (which studied horizontal merger incentives in the presence of exclusive vertical relationships). This bargaining solution is a set of transfer prices between "upstream" and "downstream" firms in which the price negotiated between any pair of firms is the Nash bargaining solution (Nash 1950) for that pair given that all other pairs reach agreement. Because this solution can be cast as a "Nash equilibrium in Nash bargains"- that is, separate bilateral Nash bargaining problems within a Nash equilibrium to a game played among all pairs of firms - we refer to it as the "Nash-in-Nash" solution. ${ }^{4}$ The Nash-in-Nash solution provides easily computable payments for complicated environments with interdependencies. It is also based on marginal valuations, which fits well with classical price theory. Yet the Nashin-Nash solution has been criticized by some as an ad hoc solution that nests a cooperative game theory concept of Nash bargaining within a noncooperative Nash equilibrium. Noncooperative microfoundations for the Nash-in-Nash solution that have been previously developed generally have assumed that firms do not use all the information that may be at their disposal at any point in time; that is, most use "delegated agent" models in which firms involved in multiple bilateral bargains rely on separate agents for each negotiation, and agents (even those from the same firm) cannot communicate with one another during the course of bargaining. ${ }^{5}$

The purpose of this paper is to provide support for the Nash-in-Nash solution as a viable surplus division rule in the applied analysis of bilateral oligopoly by specifying a noncooperative microfoundation that does not require firms to behave independently (or "schizophrenically") across bargains. We contribute to the "Nash program" of pairing noncooperative and axiomatic approaches to strategic bargaining problems (cf. Binmore 1987; Serrano 2005) and share the same motivation as Binmore, Rubinstein, and Wolinsky (1986), who sought to "provide a more solid grounding for applications of the Nash bargaining solution in economic modeling" (176). We develop a simple extensive form bargaining game that extends their anal-

\footnotetext{
${ }^{4}$ Crucially, this solution assumes that each bilateral pair bargains as if the negotiated prices (or contracts) of all other pairs of firms do not adjust in response to a bargaining disagreement or breakdown. The Nash-in-Nash solution is a type of contract equilibrium as defined in Cremer and Riordan (1987) and has also been employed in several theoretical papers including Davidson (1988), Dobson (1994), Björnerstedt and Stennek (2007), Dobson and Waterson (2007), Iozzi and Valletti (2014), and Inderst and Montez (forthcoming).

${ }^{5}$ For instance, Crawford and Yurukoglu (2012) sketch a noncooperative extensive form game generating this solution, writing, "Each distributor and each conglomerate send separate representatives to each meeting. Once negotiations start, representatives of the same firm do not coordinate with each other. We view this absence of informational asymmetries as a weakness of the bargaining model" (659). See also Chipty and Snyder (1999) and Björnerstedt and Stennek (2007).
} 
ysis and the classic Rubinstein (1982) model of alternating offers between two parties to the bilateral oligopoly case with multiple upstream and downstream firms. Focusing on environments in which transfer prices between firms are lump-sum and there are gains from trade between every pair of firms that are allowed to contract, we prove two main sets of results.

The first set of results provides sufficient conditions for the existence of a Nash-in-Nash limit equilibrium, that is, an equilibrium in which all allowed agreements are formed, with formation at prices that are arbitrarily close to the Nash-in-Nash solution when the time between offers is sufficiently short. Our conditions place limits on the extent to which the sum of a firm's marginal gains from individual agreements within a set can exceed its marginal gains from the entire set of agreements. These conditions are satisfied in environments in which firms on the same side of the market are substitutes for one another, and also in environments with limited complementarities.

Our second set of results concerns the uniqueness of equilibrium prices. We prove that any no-delay equilibrium - that is, an equilibrium in which all allowed agreements (that have not yet been formed) form immediately following every history of play (as is the case for the equilibria that we construct for our existence results) — must have agreements that form at prices that are arbitrarily close to the Nash-in-Nash solution when the time between offers is sufficiently short. We also provide sufficient conditions for all equilibria to have this property without conditioning on no-delay equilibria. Our results do not restrict attention to stationary strategies, as is the case with refinements such as Markov perfect equilibrium.

We believe that our work has three general takeaways. First, by extending the Binmore et al. (1986) noncooperative foundation for Nash bargaining to environments with multiple upstream and downstream firms, we provide a microfoundation for applied work using the Nash-in-Nash solution as a surplus division rule in bilateral oligopoly. Second, our equilibrium existence results clarify when and provide conditions under which Nash-in-Nash may be an appropriate solution concept. Finally, our uniqueness results suggest that the Nash-in-Nash solution may be a relatively robust outcome across a variety of settings.

Overview.-We now briefly discuss our model, results, and proofs. We consider the class of bilateral oligopoly games in which firm profits (net of negotiated transfers) depend only on the set of bilateral agreements that have been formed between upstream and downstream firms. We condition on the set of agreements that can be formed and assume that there are gains from trade from each agreement within that set (given that all other agreements in that set form). Our extensive form game adapts the Rubinstein (1982) bargaining protocol to a setting with multiple agents. In odd periods, each downstream firm makes simultaneous private offers to each upstream firm with which it has not yet formed an agreement; each up- 
stream firm then accepts or rejects any subset of its offers. In even periods, roles are reversed, with upstream firms making private offers and downstream firms accepting or rejecting them. If an offer is accepted, a fixed lump-sum payment is made and an agreement forms between the two firms. At the end of each period, the set (or "network") of agreements that has been formed is observed by all firms, and upstream and downstream firms earn flow profits. These profits, assumed to be a primitive of the analysis, are a function only of the set of agreements formed up to that point and allow for flexible interdependencies across agreements. However, this rules out settings in which these profits depend also on the terms of agreement (see Sec. V for further discussion) ${ }^{6}$ Crucially, our model admits the possibility that a firm can engage in deviations across multiple negotiations and also optimally respond to information acquired from one of its negotiations in others.

Our game has imperfect information since, within a period, firms do not see offers for agreements that do not involve them. We employ purestrategy weak perfect Bayesian equilibrium with passive beliefs as our solution concept. Passive beliefs restrict firms to believe, upon receiving an off-the-equilibrium-path offer, that all unobserved actions remain equilibrium actions. This solution concept has been widely used and employed in the vertical contracting literature to analyze similar types of problems (cf. Hart and Tirole 1990; McAfee and Schwartz 1994).

We provide two sets of conditions that ensure the existence of a Nash-inNash limit equilibrium. The first set is a single assumption that we refer to as weak conditional decreasing marginal contributions (abbreviated as A.WCDMC, where "A." refers to assumption). It requires that the marginal contribution from any set of agreements be no less than the sum of the marginal contributions from each individual agreement within that set for all firms when all other agreements have been formed. A.WCDMC is implied if firms on the same side of the market were viewed as at least weak substitutes by the other side. We show that A.WCDMC is necessary and sufficient for there to exist an equilibrium of our bargaining game in which agreements form immediately at prices that correspond to the pairwise Rubinstein (1982) prices for each pair of firms (given that all other firms reach agreement). These prices converge to the Nash-in-Nash solution as the length of time between offers goes to zero (Binmore et al. 1986).

Our second set of conditions is a pair of assumptions that simultaneously weaken A.WCDMC for one side of the market (i.e., either upstream or downstream firms) and strengthen it for the other side, thereby extending the settings under which our results apply. The weaker assumptionfeasibility (A.FEAS) - states that the marginal profits to each firm from any

${ }^{6}$ For example, this includes settings in which agreements specify linear wholesale prices, and downstream firms then engage in price competition for consumers. 
set of its agreements are weakly greater than the sum of the Nash-in-Nash prices that are paid or received for those agreements. ${ }^{7}$ A.WCDMC implies A.FEAS. The stronger assumption-strong conditional decreasing marginal contributions (A.SCDMC) - states that the marginal contributions to each firm from an agreement are lower when all other agreements have been formed than when certain subsets of agreements have been formed. A.SCDMC implies A.WCDMC. We prove that A.FEAS is necessary for there to exist a Nash-in-Nash limit equilibrium in which all agreements form immediately and is sufficient when combined with A.SCDMC holding for one side of the market. We view our existence results to be the most important from the point of view of applied work, as they provide conditions under which the Nash-in-Nash solution may be viewed as a reasonable surplus division rule.

We prove two results concerning the uniqueness of equilibrium outcomes. The first result is that, in any no-delay equilibrium, all agreements are formed at prices that are arbitrarily close to the Nash-in-Nash solution when the time between offers is sufficiently short. The bargaining literature has sometimes restricted attention to no-delay equilibria (e.g., Ray and Vohra 2015), and we believe that our first uniqueness result highlights the robustness of the Nash-in-Nash solution in environments in which delay is unlikely to occur. The second result - proven without conditioning on immediate agreement - is that all equilibria involve all agreements (that have not yet been formed) forming immediately at the pairwise Rubinstein (1982) prices, given a restriction on how firms break ties when indifferent over best responses and two assumptions on profits that are stronger than those used to prove existence. In particular, we assume that both upstream and downstream firm profits satisfy our stronger decreasing returns assumption used to establish existence (A.SCDMC) and also satisfy a limited negative externalities assumption (A.LNEXT). We prove our second uniqueness result via induction on the set of agreements formed at any point in time and leverage (i) our timing assumptions that allow for multiple offers to be made and multiple agreements formed at any period, (ii) the fact that our candidate equilibrium prices make a firm indifferent between accepting an offer and rejecting it (and forming the agreement in the next period), and (iii) our stronger assumptions on profits to rule out the possibility that some agreements do not immediately form following any history of play.

Related literature.-Although our results complement a broader theoretical literature that examines vertical contracting in industrial organization settings (e.g., Hart and Tirole 1990; O'Brien and Shaffer 1992; McAfee and Schwartz 1994; Segal 1999; Rey and Vergé 2004; cf. Whinston

\footnotetext{
${ }^{7}$ Since downstream firms pay upstream firms, payments are the prices for downstream firms and the negative of the prices for upstream firms.
} 
2006), our modeling approach is most similar to that adopted by the literature on wage bargaining (e.g., Davidson 1988; Horn and Wolinsky 1988b; Jun 1989; Stole and Zwiebel 1996; Westermark 2003; Brügemann, Gautier, and Menzio 2017). The wage bargaining literature typically examines extensive form bargaining games between a single firm and multiple workers (or a single union and multiple firms) and uses a payoff structure that is a special case of ours (i.e., multiple upstream firms, or workers, bargaining with a single downstream firm that accrues all profits). Part of this literature has analyzed games under which workers are paid according to the Nash-in-Nash solution as the period length between offers goes to zero; we generalize some of these results. ${ }^{8}$

Other papers in the wage bargaining literature, including Stole and Zwiebel (1996) and Brügemann et al. (2017), provide alternative games under which Shapley values emerge as the division of surplus; both of these papers adopt the assumption that following a breakdown in negotiation between a firm and any given worker, all other negotiations restart and begin anew with any worker previously involved in a breakdown no longer involved in bargaining. Similar to papers that have provided extensive form representations of the generalization of the Shapley value to networked or bilateral oligopoly settings - by relying on renegotiation following disagreement (Navarro and Perea 2013) or contracts that are contingent on the set of realized agreements (Inderst and Wey 2003; de Fontenay and Gans 2014) — our paper extends the settings under which the Nash-in-Nash solution emerges as an equilibrium outcome. ${ }^{9}$ We further discuss the relationship between extensive form representations and surplus division rules in Section $\mathrm{V}$.

Our focus on environments in which contracts are bilaterally negotiated and the network of agreements matters in determining profits distinguishes our analysis from a broader literature on multilateral and coalitional bargaining and contracting, both with and without externalities (e.g., Chatterjee et al. 1993; Chae and Yang 1994; Merlo and Wilson 1995; Krishna and Serrano 1996; Gomes 2005; Ray and Vohra 2015). ${ }^{10}$

${ }^{8}$ For example, both Jun (1989) and Westermark (2003) analyze bargaining between a single firm and two workers. One of Jun's settings is a special case of our model with one downstream firm, two upstream firms, equal discounting factors, and profits only on the downstream side. Our existence results in theorem 3.4 generalize the equilibrium construction in Jun's study to multiple upstream and downstream firms, where profits for both sides can be nonzero. Westermark's game form also uses an alternating offers framework but, in contrast to our setting, assumes that offers are made sequentially with randomly determined proposers. Montez (2014) examines a one-to-many bargaining environment in which agreements are nonrenegotiable and a principal may be able to declare bankruptcy in the event of disagreement.

${ }^{9}$ Also related to our paper is a literature that examines the trade of goods in fixed networks (e.g., Corominas-Bosch 2004; Polanski 2007; Manea 2011; Elliott 2015); most of this literature rules out externalities from trades that do not involve a given buyer or seller.

${ }^{10}$ In many applied settings, side payments among firms on the same side of the market (or between firms without a contractual relationship) would generally violate antitrust laws. 
Finally, many of the assumptions that we use have analogues in the literatures previously mentioned as well as in the network formation literature. This literature examines conditions under which efficient or pairwise stable networks form but is not primarily concerned with the division of surplus (e.g., Bloch and Jackson 2007; Hellmann 2013). ${ }^{11}$

The remainder of our paper is organized as follows. Section II describes our extensive form bargaining model and our equilibrium concept. Section III provides our assumptions and results for the existence of Nash-inNash limit equilibria. Section IV provides our assumptions and results for the uniqueness of equilibrium outcomes. Section $\mathrm{V}$ discusses connections between our results and the applied literature, as well as directions for future work. Section VI presents concluding remarks.

\section{Model}

Consider the bipartite negotiations between $N$ upstream firms, $U_{1}, U_{2}, \ldots$, $U_{N}$, and $M$ downstream firms, $D_{1}, D_{2}, \ldots, D_{M}$. We permit agreements to be formed only between upstream and downstream firms and not between firms on the same "side" of the market. ${ }^{12}$ Let $\mathcal{G}$ represent the set of potential or feasible agreements; $\mathcal{G}$ can be represented by a bipartite network between upstream and downstream firms. ${ }^{13}$ Denote a potential agreement between $U_{i}$ and $D_{j}$ as $i j$; the set of agreements that $U_{i}$ can form as $\mathcal{G}_{i, U}$; and the set of agreements that $D_{j}$ can form as $\mathcal{G}_{j, D}$. For any subset of agreements $\mathcal{A} \subseteq \mathcal{G}$, let $\mathcal{A}_{j, D} \equiv \mathcal{A} \cap \mathcal{G}_{j, D}$ denote the set of agreements in $\mathcal{A}$ that involve firm $D_{j}$, and let $\mathcal{A}_{-j, D} \equiv \mathcal{A} \backslash \mathcal{A}_{j, D}$ denote the set of all agreements in $\mathcal{A}$ that do not involve $D_{j}$. Define $\mathcal{A}_{i, U}$ and $\mathcal{A}_{-i, U}$ analogously.

We take as primitives profit functions $\left\{\pi_{i, U}(\mathcal{A})\right\}_{i=1, \ldots, N ; \mathcal{A} \subseteq \mathcal{G}}$ and $\left\{\boldsymbol{\pi}_{j, D}(\mathcal{A})\right\}_{j=1, \ldots, M ; \mathcal{A} \subseteq \mathcal{G}}$, which represent the surpluses realized by upstream

\footnotetext{
${ }^{11}$ For example, our A.WCDMC assumption is analogous to Bloch and Jackson's "superadditive in own-links" property, and our A.LNEXT is strictly weaker than their "nonnegative externalities" assumption. In addition, our A.SCDMC assumption is related to Hellmann's (2013) "strategic substitutes" property. We discuss these connections further when our assumptions are formally introduced.

${ }^{12}$ In many-market settings, contractual agreements between two firms on the same side of the market can be interpreted as collusion and hence may constitute per se antitrust violations. Alternatively, agreements between two firms on the same side of the market can be viewed as a horizontal merger, in which case our analysis would treat those merged firms as one entity. We do not explicitly model the determination of such mergers in this paper. Additionally, vertical integration and price formation, as modeled in de Fontenay and Gans (2005), are also outside the scope of the paper.

${ }^{13}$ Note that $\mathcal{G}$ need not contain all agreements between all upstream and downstream firm pairs; some agreements may be infeasible or impossible to form. As in Lee and Fong (2013), there may be a prior network formation game that leads to a set of agreements $\mathcal{G}$ being feasible before bargaining commences. A model that determines the realized set of agreements is outside the scope of this paper, as we focus on the determination of transfers given the set of agreements $\mathcal{G}$.
} 
and downstream firms for a set or "network" of agreements that have been formed at any point in time; these do not include transfers. Importantly, profits from an agreement may depend on the set of other agreements formed; this allows for profit interdependencies and externalities across agreements. We assume that each upstream firm $U_{i}$ and downstream firm $D_{j}$ negotiate over a lump-sum payment (or "price") $p_{i j}$ paid from $D_{j}$ to $U_{i}$ in exchange for forming an agreement; this implies that profits (not including transfers) depend on the set of agreements formed but not on the negotiated prices. ${ }^{14}$

We model a dynamic game with infinitely many discrete periods. Periods are indexed $t=1,2,3, \ldots$, and the time between periods is $\Lambda>0$. Total payoffs (profits and prices) for each firm are discounted. The discount factors between periods for an upstream and a downstream firm are represented by $\delta_{i, U} \equiv \exp \left(-r_{i, U} \Lambda\right)$ and $\delta_{j, D} \equiv \exp \left(-r_{j, D} \Lambda\right)$, respectively.

The game begins in period $t_{0} \geq 1$ with no agreements in $\mathcal{G}$ formed; that is, all agreements in $\mathcal{G}$ are "open." In odd periods, each downstream firm $D_{j}$ simultaneously makes private offers $\left\{p_{i j}\right\}_{i j \in \mathcal{G}_{j, D}}$ to each $U_{i}$ in $\mathcal{G}_{j, D}$ with which it does not yet have an agreement; each upstream firm $U_{i}$ then simultaneously accepts or rejects any offers it receives. In even periods, each $U_{i}$ simultaneously makes private offers $\left\{p_{i j}\right\}_{i j \in \mathcal{G}_{i, U}}$ to downstream firms with which it does not yet have an agreement; each $D_{j}$ then simultaneously accepts or rejects any offers that it receives. If $D_{j}$ accepts an offer from $U_{i}$ or $U_{i}$ accepts an offer from $D_{j}$, then an agreement is formed between the two firms, and that agreement remains "formed" for the rest of the game. Each $U_{i}$ receives its payment of $p_{i j}$ from $D_{j}$ immediately in the period in which an agreement is formed.

We assume that within a period, a firm observes only the set of contracts that it offers or that are offered to it. However, at the end of any period, all information - including the terms of every contract, accepted or not-is observed by every firm; this implies that at the beginning of each period, every firm observes and can condition its strategies on a common history of play. ${ }^{15}$ This history, denoted $h^{t}$, is the set of all actions (price offers and acceptances or rejections) that have been made by every firm in all periods prior to $t$. We denote by $\mathcal{C}\left(h^{t}\right)$ the set of open agreements at history $h^{t}$.

${ }^{14}$ See Sec. V for further discussion on this point.

${ }_{15}$ We make this assumption for tractability, as our approach would be difficult without being able to condition on a common history of play. Institutionally, the bilaterally contracted price between firms may not be observable to others (e.g., for competitive or antitrust concerns). The vertical contracting literature has considered how private offers may lead to commitment and opportunism (Hart and Tirole 1990; O'Brien and Shaffer 1992; McAfee and Schwartz 1994). Using a delegated agent model, de Fontenay and Gans (2005) examine the impact of vertical integration on bargaining assuming that agents do not observe the terms of contracts that do not involve them. 

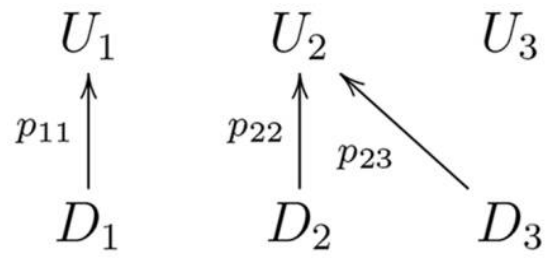

FIG. 1.-Example: market with three agreements already formed

At the end of each period (after lump-sum payments from new agreements have been made), each upstream firm $U_{i}$ and downstream firm $D_{j}$ receives a flow payment equal to $\left(1-\delta_{i, U}\right) \pi_{i, U}(\mathcal{A})$ or $\left(1-\delta_{j, D}\right) \pi_{j, D}(\mathcal{A})$ (respectively), where $\mathcal{A}$ is the set of agreements that has been formed up to that point in time. ${ }^{16}$

EXAMPLE. Figure 1 depicts a potential market with three upstream and three downstream firms. Assume that in period 1, the set of agreements $\mathcal{A}^{1} \equiv\{11,22,23\}$ forms. This implies that in period $1, U_{1}$ receives a payment $p_{11}$ from $D_{1}$, and $U_{2}$ receives $p_{22}$ from $D_{2}$ and $p_{23}$ from $D_{3}$; in the same period, each downstream firm $D_{j}$ receives flow profits $\left(1-\delta_{j, D}\right) \pi_{j, D}\left(\mathcal{A}^{1}\right)$ and each upstream firm $U_{i}$ receives flow profits $\left(1-\delta_{i, U}\right) \pi_{i, U}\left(\mathcal{A}^{1}\right)$. If, in period 2, $D_{1}$ forms an agreement with $U_{2}$ at some price $p_{21}$ (and that is the only agreement that is formed), $D_{1}$ would pay $U_{2}$ a payment $p_{21}$ in period 2, and all firms would earn period 2 flow profits as a function of the new realized set of agreements, $\mathcal{A}^{2} \equiv \mathcal{A}^{1} \cup\{12\}$.

Two points about our model are worth noting. First, while the flow profits continue to accrue to all firms forever, no additional actions are taken after the last agreement is formed. Thus, the game can also be formulated to end in the period of last agreement, with each upstream firm $U_{i}$ realizing a one-time payoff of $\left(1-\delta_{i, U}\right) \pi_{i, U}(\mathcal{G}) /\left(1-\delta_{i, U}\right)=\pi_{i, U}(\mathcal{G})$ (and analogously for each downstream firm). Second, if $M=N=1$, our game is equivalent to the Rubinstein (1982) alternating offers model.

\section{A. Equilibrium Concept}

We use pure-strategy weak perfect Bayesian equilibrium as our solution concept. This differs from Rubinstein (1982) — which considers subgame perfect equilibria - because our model has imperfect information within a period (i.e., a firm observes only offers that it makes or receives). Weak

\footnotetext{
${ }^{16}$ Our model can also be recast without discounting but with an exogenous probability each period that negotiations end and with lump-sum payments based on the set of all agreements that has been formed when negotiations end (see Binmore et al. 1986). In our model, externalities across firms generate endogenous "inside options" rather than "outside options" (Muthoo 1999) since flow payments depend on the set of agreements that has been formed.
} 
perfect Bayesian equilibrium does not place restrictions on beliefs for information sets that are not reached in equilibrium and hence may admit many equilibrium outcomes. To refine our predictions further, we follow the literature on vertical contracting (e.g., Hart and Tirole 1990; O'Brien and Shaffer 1992; McAfee and Schwartz 1994; Segal 1999; de Fontenay and Gans 2014) and restrict firms to hold passive beliefs.

Passive Beliefs. At any period $t$ information set with history $h^{t}$, each firm's beliefs over actions that it does not observe are consistent with equilibrium play at $h^{t}$, even if its information set reflects actions that are not consistent with equilibrium play at $h^{t}$.

The assumption of passive beliefs is a key ingredient in many of the results of the literature on vertical contracting and opportunism and in our setting restricts how beliefs can change following an off-the-equilibriumpath (henceforth, off-equilibrium) action. ${ }^{17}$ For example, this assumption implies that an upstream firm $U_{i}$, upon receiving an off-equilibrium price offer from some $D_{j}$ in period $t$ following history $h^{t}$, believes that all other offers made by $D_{j}$ and actions taken by other firms remain equilibrium actions. Henceforth, we use equilibrium to refer to a pure-strategy weak perfect Bayesian equilibrium with passive beliefs.

\section{B. Nash-in-Nash and Rubinstein Prices}

For exposition, it will be useful to define $\Delta \pi_{i, U}(\mathcal{A}, \mathcal{B}) \equiv \pi_{i, U}(\mathcal{A})-$ $\pi_{i, U}(\mathcal{A} \backslash \mathcal{B})$, for $\mathcal{B} \subseteq \mathcal{A} \subseteq \mathcal{G}$. This term is the increase in profits to $U_{i}$ of adding agreements in $\mathcal{B}$ to the set of agreements $\mathcal{A} \backslash \mathcal{B}$. We refer to $\Delta \pi_{i, U}(\mathcal{A}, \mathcal{B})$ as the marginal contribution to $U_{i}$ of agreements $\mathcal{B}$ at $\mathcal{A}$. Correspondingly, let $\Delta \pi_{j, D}(\mathcal{A}, \mathcal{B}) \equiv \pi_{j, D}(\mathcal{A})-\pi_{j, D}(\mathcal{A} \backslash \mathcal{B})$. Importantly, as in Bloch and Jackson (2007), we define the marginal contribution of a set of agreements $\mathcal{B}$ as their value relative to removing them from the larger set $\mathcal{A}$ that includes $\mathcal{B}$.

For analysis, we assume that for any $i j \in \mathcal{G}$, the joint surplus created by $U_{i}$ and $D_{j}$ coming to an agreement (given that all other agreements in $\mathcal{G}$ have been formed) is positive.

Assumption A.GFT (Gains from trade). $\Delta \pi_{i, U}(\mathcal{G},\{i j\})+\Delta \pi_{j, D}(\mathcal{G},\{i j\})>$ 0 for all $i j \in \mathcal{G}$.

This assumption implies that each pair of firms that can form an agreement in $\mathcal{G}$ has an incentive to keep that agreement given that all other agreements in $\mathcal{G}$ form. We believe that it is natural in many settings of interest as without A.GFT, firms may prefer to drop any agreements in

17 The vertical contracting literature has recognized an implicit relationship between passive beliefs and the Nash-in-Nash solution: e.g., Rey and Vergé (2004, 729) state that "Horn and Wolinsky (1988) use a bilateral Nash bargaining approach that also relates somewhat to passive beliefs." It is possible that other belief restrictions may lead to different results (cf. McAfee and Schwartz 1994; Rey and Vergé 2004). 
which there are losses from trade. Rubinstein (1982) implies A.GFT as his first assumption, naming it "[the] 'pie' is desirable."

We now define "Nash-in-Nash" and "Rubinstein" prices for our game. Assume that A.GFT holds. For a given set of agreements $\mathcal{G}$ and set of positive bargaining weights $\left\{b_{i, U}\right\}_{\forall i}$ and $\left\{b_{j, D}\right\}_{\forall j}$, Nash-in-Nash prices are a vector of prices $\left\{p_{i j}^{\text {Nash }}\right\}_{\forall i j \in \mathcal{G}}$ such that, for all $i j \in \mathcal{G}$,

$$
\begin{aligned}
p_{i j}^{\mathrm{Nash}} & \equiv \arg \max _{p}\left[\Delta \pi_{j, D}(\mathcal{G},\{i j\})-p\right]^{b_{j, D}} \times\left[\Delta \pi_{i, U}(\mathcal{G},\{i j\})+p\right]^{b_{i, U}} \\
& =\frac{b_{i, U} \Delta \pi_{j, D}(\mathcal{G},\{i j\})-b_{j, D} \Delta \pi_{i, U}(\mathcal{G},\{i j\})}{b_{i, U}+b_{j, D}} .
\end{aligned}
$$

Each price $p_{i j}^{\text {Nash }}$ corresponds to the Nash bargaining solution between $D_{j}$ and $U_{i}$ given that all other agreements in $\mathcal{G}$ are formed.

For a given set of agreements $\mathcal{G}$, Rubinstein prices are a vector of prices $\left\{p_{i j, D}^{R}, p_{i j, U}^{R}\right\}_{\forall i j \in \mathcal{G}}$ such that, for all $i j \in \mathcal{G}$,

$$
\begin{aligned}
p_{i j, D}^{R} & =\frac{\delta_{i, U}\left(1-\delta_{j, D}\right) \Delta \pi_{j, D}(\mathcal{G},\{i j\})-\left(1-\delta_{i, U}\right) \Delta \pi_{i, U}(\mathcal{G},\{i j\})}{1-\delta_{i, U} \delta_{j, D}}, \\
p_{i j, U}^{R} & =\frac{\left(1-\delta_{j, D}\right) \Delta \pi_{j, D}(\mathcal{G},\{i j\})-\delta_{j, D}\left(1-\delta_{i, U}\right) \Delta \pi_{i, U}(\mathcal{G},\{i j\})}{1-\delta_{i, U} \delta_{j, D}} .
\end{aligned}
$$

Each pair of prices $\left\{p_{i j, D}^{R}, p_{i j, U}^{R}\right\}$ correspond to the offers made in odd or even periods when $D_{j}$ and $U_{i}$ engage in a Rubinstein (1982) alternating offers bargaining game given that all other agreements in $\mathcal{G}$ are formed.

Let the Nash bargaining weights be parameterized so that $b_{j, D}=$ $r_{i, U} /\left(r_{i, U}+r_{j, D}\right)$ and $b_{i, U}=r_{j, D} /\left(r_{i, U}+r_{j, D}\right)$. Then, as noted in Binmore et al. (1986), Rubinstein prices converge to the Nash-in-Nash prices as the time between offers becomes arbitrarily short.

Lemma 2.1. $\lim _{\Lambda \rightarrow 0} p_{i j, D}^{R}=\lim _{\Lambda \rightarrow 0} p_{i j, U}^{R}=p_{i j}^{\text {Nash }}$.

(All proofs are in the appendixes, available online.)

There are properties of Rubinstein and Nash-in-Nash prices that will prove crucial in our proofs. First, Rubinstein prices make the receiving agent indifferent between accepting its offer and waiting until the next period and having its counteroffer accepted given that all other agreements form. In our case, in an even (upstream-proposing) period, this implies that downstream firms are indifferent between accepting an offer and waiting until the next period (given that it believes that all agreements $\mathcal{G} \backslash\{i j\}$ have been or will be formed). Equivalently,

$$
\underbrace{\left(1-\delta_{j, D}\right) \Delta \pi_{j, D}(\mathcal{G},\{i j\})}_{\text {Loss in profit from waiting }}=\underbrace{p_{i j, U}^{R}-\delta_{j, D} p_{i j, D}^{R}}_{\text {Decrease in transfer payment from waiting }}
$$


for all $i j \in \mathcal{G}$. Correspondingly, for upstream firms in odd periods,

$$
\left(1-\delta_{i, U}\right) \Delta \pi_{i, U}(\mathcal{G},\{i j\})=\delta_{i, U} p_{i j, U}^{R}-p_{i j, D}^{R} \quad \forall i j \in \mathcal{G} .
$$

Second, the value from agreement to each party is higher than prices paid or received, and Nash-in-Nash prices lie between the upstream and downstream proposing Rubinstein prices.

Lemma 2.2. Assume A.GFT. Then for all $i j \in \mathcal{G}$,

$$
\begin{gathered}
\Delta \pi_{j, D}(\mathcal{G},\{i j\})>p_{i j, U}^{R}>p_{i j, D}^{R}, \\
\Delta \pi_{i, U}(\mathcal{G},\{i j\})>-p_{i j, D}^{R}>-p_{i j, U}^{R}, \\
p_{i j, U}^{R}>p_{i j}^{\mathrm{Nash}}>p_{i j, D}^{R} .
\end{gathered}
$$

\section{A Delegated Agent Model for Nash-in-Nash Prices}

Before proceeding, in this subsection we detail an alternative "delegated agents" extensive form that generates Nash-in-Nash prices as $\Lambda \rightarrow 0$ (see also Chipty and Snyder 1999; Björnerstedt and Stennek 2007). In this model, firms appoint separate agents to conduct each bilateral bargain. Each bargain follows the alternating offers protocol based on Binmore et al. (1986): there is no discounting, but each bargain breaks down with a fixed exogenous probability - that is independent across bargains - at the end of every period, if an agreement has not yet been formed. Agents do not know the outcome of other bilateral bargains until their own bargain has concluded (by either breaking down or forming). Payments are made on the basis of the set of agreements that has been formed after all bargains have concluded.

In appendix A, we prove that A.GFT is sufficient for there to exist an equilibrium in which all agreements in $\mathcal{G}$ immediately form at prices that are arbitrarily close to Nash-in-Nash prices as the probability of a bilateral bargain breaking down in each period goes to zero. However, this alternative model may be viewed as unsatisfying: firms do not leverage information learned in one negotiation in another and cannot coordinate actions across different concurrent negotiations.

\section{Equilibrium Existence}

Our paper is concerned with equilibrium outcomes of our bargaining game as the time between offers becomes arbitrarily short. For this purpose, we define the concept of a Nash-in-Nash limit equilibrium. We say that a Nash-in-Nash limit equilibrium exists if, for any $\varepsilon>0$ and $t_{0}$, there exists a $\bar{\Lambda}>0$ such that, for all $\Lambda \in(0, \bar{\Lambda}]$, there is an equilibrium with complete 
agreement (i.e., in which all agreements in $\mathcal{G}$ are formed) and in which all agreements are formed at prices that are within $\varepsilon$ of Nash-in-Nash prices.

\section{A. Equilibrium Existence at Rubinstein Prices}

We first present a necessary and sufficient condition for there to exist an equilibrium of the bargaining game in which, for any $\Lambda>0$, all open agreements at any history of play immediately form at Rubinstein prices. Since Rubinstein prices converge to Nash-in-Nash prices as $\Lambda \rightarrow 0$ (by lemma 2.1), this guarantees that a Nash-in-Nash limit equilibrium exists.

Assumption A.WCDMC (Weak conditional decreasing marginal contribution). For upstream firms, for all $i=1, \ldots, N$ and all $\mathcal{A} \subseteq \mathcal{G}_{i, U}$,

$$
\Delta \pi_{i, U}(\mathcal{G}, \mathcal{A}) \geq \sum_{i k \in \mathcal{A}} \Delta \pi_{i, u}(\mathcal{G},\{i k\}) .
$$

For downstream firms, for all $j=1, \ldots, M$ and all $\mathcal{A} \subseteq \mathcal{G}_{j, D}$,

$$
\Delta \pi_{j, D}(\mathcal{G}, \mathcal{A}) \geq \sum_{h j \in \mathcal{A}} \Delta \pi_{j, D}(\mathcal{G},\{h j\}) .
$$

This condition states that, for both upstream and downstream firms, the marginal contribution of any set of agreements to a firm is weakly greater than the sum of the marginal contributions of each individual agreement within the set when all other agreements in $\mathcal{G}$ have formed. This condition will generally be satisfied if firms on the same side of the market are substitutes, rather than complements, for firms on the other side of the market. Similar conditions have been used in the network formation and wage bargaining literature (e.g., Stole and Zwiebel 1996; Westermark 2003; Bloch and Jackson 2007; Hellmann 2013). For example, using Bloch and Jackson's terminology, A.WCDMC is equivalent to assuming that profit functions for all firms are superadditive in own links at $\mathcal{G}{ }^{18}$

We now state our first existence result:

Theorem 3.1 (Existence at Rubinstein prices). Assume A.GFT. For any $\Lambda>0$, there exists an equilibrium of the bargaining game in which at every period $t$ and history $h^{t}$, all open agreements $i j \in \mathcal{C}\left(h^{t}\right)$ immediately form at prices $p_{i j, D}^{R}\left(p_{i j, U}^{R}\right)$ if $t$ is odd (even) if and only if A.WCDMC holds. The proof of theorem 3.1, contained in appendix C, constructs candidate equilibrium strategies based on the above statement and then confirms that these strategies are robust to one-shot deviations by any firm. Furthermore, it demonstrates that if A.WCDMC does not hold for some firm and a subset of its agreements, then that firm-when deciding to

\footnotetext{
${ }_{18}$ Bloch and Jackson (2007) define superadditivity in own links as a condition analogous to A.WCDMC holding at any network, and not just at $\mathcal{G}$; Hellmann (2013) refers to their assumption as "convex in own current links."
} 
accept or reject that set of offers at Rubinstein prices-would have a profitable deviation of rejecting those offers. ${ }^{19}$

A.WCDMC rules out the possibility that any agent would wish not to form or delay forming any subset of its open agreements at Rubinstein prices. To see this, without loss of generality, consider any upstream firm $U_{i}$ in an odd (downstream-proposing) period and any subset of its agreements $\mathcal{A} \subseteq \mathcal{G}_{i, U}$. A.WCDMC implies that the gain to $U_{i}$ from accepting the agreements in $\mathcal{A}$ (given that all other agreements are formed) is weakly greater than the gain from rejecting the offers in $\mathcal{A}$ and forming the agreements in $\mathcal{A}$ in the subsequent period at candidate equilibrium prices; that is,

$$
\begin{aligned}
& \text { Change in } U_{i} \text { 's profits by forming agreements } \mathcal{A} \text { in period } t \text { as opposed to } t+1 \\
& \overbrace{\left(1-\delta_{i, U}\right) \Delta \pi_{i, U}(\mathcal{G}, \mathcal{A})+\sum_{i k \in \mathcal{A}}\left[p_{i k, D}^{R}-\delta_{i, U} p_{i k, U}^{R}\right]} \\
& \geq \sum_{i k \in \mathcal{A}}\left[\left(1-\delta_{i, U}\right) \Delta \pi_{i, U}(\mathcal{G},\{i k\})+p_{i k, D}^{R}-\delta_{i, U} p_{i k, U}^{R}\right]=0,
\end{aligned}
$$

where the inequality follows from A.WCDMC and the equality from (2). A similar inequality shows that each downstream firm $D_{j}$ in even (upstreamproposing) periods would not wish to reject any subset of offers that it receives at even-period Rubinstein prices.

We illustrate the necessity of A.WCDMC for the existence of an equilibrium with immediate agreement at Rubinstein prices with two counterexamples. Consider first a setting in which there are large complementarities across agreements. Assume that there are three upstream parts "suppliers" that each provide a necessary component to a downstream "manufacturer" for production of an automobile, which is then resold for some fixed surplus; there are zero marginal costs for all firms; the manufacturer can sell the product for a surplus of 1 if all agreements are reached and 0 otherwise; and firms share a common discount factor $\delta$.

A.WCMDC does not hold here because the marginal contribution of a supplier to the manufacturer when not all agreements have been formed, at zero, is less than its marginal contribution of 1 when all agreements have been formed. The Nash-in-Nash prices here are a half of the marginal contributions when all agreements have been formed, or 0.5 . At Nash-in-Nash prices, the downstream firm would realize a loss of 0.5 (with gross profits of 1 and supplier costs of 1.5), implying that the downstream firm would not wish to reach agreement at such prices with its suppliers. In this setting, it is implausible that transfers will be based on marginal

${ }^{19}$ Proposition 3 in Bloch and Jackson (2007) shows that the network $\mathcal{G}$ is supportable as an equilibrium of a "direct transfer game" if superadditivity in own links and a condition that implies A.GFT hold. Thus, theorem 3.1 proves that the same assumptions on underlying payoffs as used in Bloch and Jackson's paper are sufficient for there to exist an equilibrium of our alternating offers bargaining game in which agreements in $\mathcal{G}$ are formed at Rubinstein prices. 
contributions: either no agreements will be reached or surplus division would be based on some other bargaining protocol or solution concept. ${ }^{20}$

Now consider a similar counterexample, but with two instead of three suppliers. We generalize the above example to assume that the manufacturer with one supplier earns profits $a, 0 \leq a<0.5$, so that the suppliers still exhibit complementarities from the perspective of the downstream firm. Note that the Rubinstein prices paid to each supplier $U_{i}$ are $p_{i 1, D}^{R}=$ $\delta(1-a) /(1+\delta)$ and $p_{i 1, U}^{R}=(1-a) /(1+\delta)$. Because profits to the manufacturer with one supplier are less than 0.5, A.WCDMC still does not hold here. Hence, by theorem 3.1, there still is no equilibrium with immediate agreement at Rubinstein prices.

To understand why an equilibrium with immediate agreement at Rubinstein prices does not exist, consider any even (upstream-proposing) period in which no agreements have yet been formed. By equation (1), the downstream firm will be exactly indifferent between $(a)$ accepting both candidate equilibrium offers and $(b)$ accepting one offer and rejecting the other (which will then be formed in the following period). In other words, the reduction in the present value of the payment from delaying an offer to the following (odd) period, $p_{i 1, U}^{R}-\delta p_{i 1, D}^{R}$, is equal to the loss in profits from this delay, $(1-\delta)(1-a)$. But the loss in profits from rejecting the second offer is only $(1-\delta) a<(1-\delta)(1-a)$ (since $a<0.5)$, while the reduction in the present value of this payment remains $(1-\delta)(1-a)$. Thus, the downstream firm would strictly prefer rejecting both offers, implying that the strategy profile from theorem 3.1 is not an equilibrium.

However, in contrast to the three-supplier example, the downstream firm here would strictly prefer agreement with both suppliers at any price below Nash-in-Nash to no agreement, as it would then obtain positive surplus instead of none (even in the limit case of perfect complements in which $a=0$ ). This suggests that a Nash-in-Nash limit equilibrium might exist here, though at prices different from Rubinstein prices. Our next results verify that this is the case.

\section{B. Equilibrium Existence with Complementarities}

We now provide an alternative set of conditions for the existence of a Nash-in-Nash limit equilibrium. Importantly, our conditions allow for limited complementarities and are not nested by A.WCDMC.

Our first condition ensures that all firms obtain value at the margin from all sets of its own agreements being formed at Nash-in-Nash prices:

Assumption A.FEAS (Feasibility). For upstream firms, for all $i=$ $1, \ldots, N$ and all $\mathcal{A} \subseteq \mathcal{G}_{i, U}$,

${ }^{20}$ This example is mathematically equivalent to example 1 in Westermark (2003), which makes a similar point with an example of a firm bargaining over wages with three workers. 


$$
\Delta \pi_{i, U}(\mathcal{G}, \mathcal{A}) \geq-\sum_{i j \in \mathcal{A}} p_{i j}^{\mathrm{Nash}}
$$

For downstream firms, for all $j=1, \ldots, M$ and all $\mathcal{A} \subseteq \mathcal{G}_{j, D}$,

$$
\Delta \pi_{j, D}(\mathcal{G}, \mathcal{A}) \geq \sum_{i j \in \mathcal{A}} p_{i j}^{\mathrm{Nash}} .
$$

In words, A.FEAS states that each firm would prefer maintaining all of its agreements at Nash-in-Nash prices to dropping any set of its agreements (holding all other agreements fixed). This is a strictly weaker condition than A.WCDMC when A.GFT holds, as Nash-in-Nash prices are then strictly less (greater) than the marginal contributions of each agreement at $\mathcal{G}$ for downstream (upstream) firms (see lemma 2.2). Similar conditions to A.FEAS have been used in other settings: for example, in Stole and Zwiebel (1996), a feasibility condition ensures that each worker receives an equilibrium wage higher than her outside wage offer. In our setting, A.GFT alone is sufficient to ensure that this condition holds for all subsets involving a single agreement (see lemma 2.2), but not for subsets that involve more than one agreement.

The following theorem demonstrates the importance of A.FEAS.

Theorem 3.2. Suppose that A.FEAS does not hold. Then a Nash-inNash limit equilibrium in which all agreements in $\mathcal{G}$ immediately form does not exist.

The proof of this theorem leverages the insight that if all agreements immediately form but A.FEAS is violated, then there exists a firm that would wish to reject (and never form) some set of its own agreements at prices that are arbitrarily close to Nash-in-Nash prices. For example, in our upstream supplier example with three suppliers, one can verify that A.FEAS does not hold for the downstream manufacturer when $\mathcal{A}$ includes all three suppliers; thus, theorem 3.2 confirms the intuition from Section III.A that there is no Nash-in-Nash limit equilibrium for this three-supplier game in which all agreements immediately form. We discuss the role of equilibria with immediate agreement further in Section IV.

The second sufficient condition that we impose to establish existence is stronger than A.WCDMC (and hence A.FEAS) and, for existence, is required to hold only for either downstream or upstream firms.

Assumption A.SCDMC (Strong conditional decreasing marginal contribution).

a. For upstream firms, for all $i j \in \mathcal{G}, \mathcal{B} \subseteq \mathcal{G}_{-j, D}$ and $\mathcal{A}, \mathcal{A}^{\prime} \subseteq \mathcal{G}_{j, D} \backslash\{i j\}$,

$$
\pi_{i, U}(\mathcal{A} \cup \mathcal{B} \cup\{i j\})-\pi_{i, U}\left(\mathcal{A}^{\prime} \cup \mathcal{B}\right) \geq \Delta \pi_{i, U}(\mathcal{G},\{i j\}) .
$$

b. For downstream firms, for all ij $\in \mathcal{G}, \mathcal{B} \subseteq \mathcal{G}_{-i, U}$ and $\mathcal{A}, \mathcal{A}^{\prime} \subseteq \mathcal{G}_{i, U} \backslash$ $\{i j\}$, 


$$
\pi_{j, D}(\mathcal{A} \cup \mathcal{B} \cup\{i j\})-\pi_{j, D}\left(\mathcal{A}^{\prime} \cup \mathcal{B}\right) \geq \Delta \pi_{j, D}(\mathcal{G},\{i j\}) .
$$

A.SCDMC $(a)$ states that the marginal contribution to any upstream firm $U_{i}$ of agreement $i j$ at $\mathcal{G}$-which is $\Delta \pi_{i, U}(\mathcal{G},\{i j\})$-is no greater than the marginal contribution to $U_{i}$ of that agreement at any subset of agreements $\mathcal{A} \cup \mathcal{B}$, even if $D_{j}$ were to change its other agreements (from $\mathcal{A}$ to $\mathcal{A}^{\prime}$ ) when making such a comparison. A.SCDMC $(b)$ states a similar condition for downstream firms. Unless explicitly noted, when we assume A.SCDMC, we assume that both parts $a$ and $b$ hold.

We rely on A.SCDMC to ensure that, whenever there are open agreements, a proposing firm would wish to make an acceptable offer and form an agreement, even if the receiving firm were to change its actions with respect to its other open agreements in that period. This rules out the possibility that an off-equilibrium offer from a proposing firm leads the receiving firm to change its set of other accepted offers, which in turn harms the proposing firm. A.SCDMC strictly implies A.WCDMC, as it places more restrictions on the marginal values of individual agreements when a subset of other agreements in $\mathcal{G}$ has formed than does A.WCDMC.

Similarly to our use of A.SCDMC, the network formation literature has often restricted the marginal contribution of a link $i j$ to be lower than the marginal contribution of that link when certain other agreements are removed; see, for instance, Hellmann's (2013) strategic substitutes property. However, A.SCDMC differs in the set of other agreements that can be removed and also that it allows the counterparty to adjust its agreements when computing the marginal contribution of an agreement to a firm. ${ }^{21}$

Before proceeding to our existence proof, we formalize the relationship of our three assumptions on marginal contributions.

Lemma 3.3. Assume that A.GFT holds. Then

a. A.SCDMC $\Rightarrow$ A.WCDMC $\Rightarrow$ A.FEAS and

b. A.FEAS $\nRightarrow$ A.WCDMC $\nRightarrow$ A.SCDMC.

We now state our final existence result.

Theorem 3.4 (Existence of a Nash-in-Nash limit equilibrium). Assume A.GFT, A.FEAS, and either A.SCDMC $(a)$ or A.SCDMC $(b)$. Then there exists a Nash-in-Nash limit equilibrium in which all agreements in $\mathcal{G}$ immediately form.

Our proof of existence in theorem 3.4 is constructive, building on insights from Jun (1989). In the equilibrium that we construct, if A.SCDMC

\footnotetext{
${ }^{21}$ An additional difference is that the pairwise stability condition often employed in the network formation literature implies that a link would be formed if the two agents involved in that link value its formation holding fixed the actions of other players. In contrast, in our setting, even if two firms would prefer to form an agreement holding fixed the actions of others, such an agreement may not form since other agreements may be affected.
} 
(a) holds, then downstream firms always propose Rubinstein prices in odd periods. ${ }^{22}$ In even periods, upstream firms propose offers that ensure that downstream firms do not want to reject a single offer or multiple offers and also ensure that every downstream firm is indifferent between complete acceptance and rejecting some subset of its offers.

If A.WCMDC holds, then by theorem 3.1 there exists an equilibrium with immediate agreement at Rubinstein prices. However, if A.SCDMC (a) holds (for upstream firms) but A.WCDMC does not hold (for downstream firms), then some downstream firm in an even period would prefer to reject some set of offers as opposed to accepting all offers at Rubinstein prices. To eliminate the incentive to reject multiple offers, the even-period equilibrium prices are then lower than even-period Rubinstein prices (though still higher than odd-period Rubinstein prices).

By not imposing A.WCDMC on one side of the market (but still requiring that A.FEAS hold for that side), theorem 3.4 admits certain forms of complementarities, thereby extending the settings under which there exists a Nash-in-Nash limit equilibrium in which all agreements in $\mathcal{G}$ immediately form, relative to theorem 3.1. For example, consider again the two upstream supplier counterexample from Section III.A. Although this example does not satisfy A.WCDMC since the suppliers produce complementary inputs, A.FEAS will be satisfied on the downstream side as long as the profits with one supplier are not negative $(a \geq 0)$. Moreover, A.SCDMC is trivially satisfied for the upstream suppliers (as they realize no flow profits). Thus, by theorem 3.4, a Nash-in-Nash limit equilibrium exists (even in the limiting case of $a=0$ ). To ensure that the manufacturer does not want to reject both offers, our constructed equilibrium for this example has even-period prices that are lower than Rubinstein prices and, in some cases, lower than Nash-in-Nash prices. ${ }^{23}$

\section{Uniqueness of Equilibrium Outcomes}

Having established results on existence, we now turn to the uniqueness of equilibrium outcomes. We prove two results. Our first result is that all nodelay equilibria - defined to be equilibria in which at any history of play $h^{t}$, all open agreements $\mathcal{C}\left(h^{t}\right)$ immediately form-have agreements formed at prices that are arbitrarily close to Nash-in-Nash prices for sufficiently short time periods. Note that the equilibria constructed to establish existence in Section III are no-delay equilibria. This result does not require

${ }^{22}$ While we focus our discussion here on the case in which A.SCMDC $(a)$ holds, the case in which A.SCDMC $(b)$ holds is analogous.

${ }^{23}$ Because the manufacturer strictly prefers accepting both even-period offers to rejecting one, we can construct multiple equilibria that differ in the payment made to each upstream firm in even periods. These equilibria all make the manufacturer indifferent between rejecting and accepting both offers in even periods, and all have prices that are arbitrarily close to Nash-in-Nash prices for sufficiently short time periods. 
any assumptions on profits, highlighting the generality of the Nash-inNash solution when agreement is immediate.

Our second result is complementary to the first and provides sufficient conditions for all equilibria to have agreements formed at Rubinstein prices (and hence at prices that are arbitrarily close to Nash-in-Nash prices for sufficiently short time periods). This second result uses the same A.SCDMC condition used to establish existence, a further assumption on profits that limits how severe negative externalities can be across agreements (A.LNEXT), and a restriction on strategies that governs how ties are broken when firms are indifferent over actions. It does not require any assumptions on equilibrium behavior (such as no-delay).

\section{A. Uniqueness for No-Delay Equilibria}

Our first theorem states that for sufficiently short time periods, any nodelay equilibrium has prices that are arbitrarily close to Nash-in-Nash prices.

Theorem 4.1 (Uniqueness for no-delay equilibria). For any $\varepsilon>0$, there exists $\bar{\Lambda}>0$ such that, for any $\Lambda \in(0, \bar{\Lambda}]$, any no-delay equilibrium has prices at every period $t$ and history $h^{t}$ that are within $\varepsilon$ of Nash-inNash prices.

Theorem 4.1 does not use any assumptions on underlying profits, but instead conditions on the immediate formation of all open agreements following all histories of play. Restricting attention to equilibria without delay is an assumption that has been used in the bargaining literature (e.g., Ray and Vohra 2015; Brügemann et al. 2017). ${ }^{24}$

The intuition of the result is as follows. Given complete and immediate agreement at every period, we first show that a receiving firm cannot receive a worse offer than its Rubinstein price in that period. If it were to receive a worse offer, a deviation for this firm would be for it to reject this offer and, in the following period when only one agreement would remain open, form the agreement at the corresponding Rubinstein price, as in Rubinstein (1982). Equations (1) and (2) ensure that such a deviation is profitable.

Next, we show that a proposing firm cannot make an offer that is accepted and significantly worse than its Nash-in-Nash price. Here, a nodelay equilibrium implies that a proposing firm anticipates that all open

\footnotetext{
${ }^{24}$ Ray and Vohra $(2015,289)$, in motivating such a restriction, note that delays in complete information bargaining models are "more artificial [than delays in bargaining with incomplete information] and stem from two possible sources. The first is a typical folk theorem like reason in which history-dependent strategies are bootstrapped to generate inefficient outcomes... . [The second] will only happen for protocols that are sensitive to the identity of previous rejectors," which is not the case for the model in Rubinstein (1982) or in our model.
} 
agreements will form in the next period, regardless of actions that are taken in the current period. If a proposing firm were to "withdraw" an offer that it is supposed to make (i.e., by making a sufficiently worse offer that would be rejected), that agreement - and potentially other agreements formed by the receiving firm-would be rejected and instead formed in the following period. Using the fact that prices in the subsequent period must be no worse for the proposing firm than Rubinstein prices (as noted above), we show that for a sufficiently short time period, a proposing firm would have a profitable deviation from withdrawing this agreement. Thus, the proposing firm would never form an agreement at a price significantly worse than the Nash-in-Nash price.

Consequently, in any no-delay equilibrium, prices must be arbitrarily close to Nash-in-Nash prices as $\Lambda \rightarrow 0$. However, we have not addressed whether there exist equilibria with delay at some histories of play. We next provide sufficient conditions on primitives and strategies to rule out this possibility.

\section{B. Uniqueness without Conditioning on Immediate Agreement}

Under stronger conditions than used to establish existence, we now prove that every equilibrium is a no-delay equilibrium in which, for any history of play, all open agreements are formed at Rubinstein prices. Under these conditions, equilibrium outcomes will be unique. If there are multiple equilibria, they will differ only in their prescribed off-equilibrium play.

The first condition requires that A.SCDMC, introduced in Section III.B and used in establishing our second existence result, holds for both upstream and downstream firms. This condition, again, states that the marginal contribution to any firm forming an agreement when all other agreements have been formed can be no greater than that agreement's contribution when certain subsets of agreements have been formed.

Our second condition is new.

Assumption A.LNEXT (Limited negative externalities). For all nonempty $\mathcal{A} \subseteq \mathcal{G}$, there exists $i j \in \mathcal{A}$ such that

$$
\begin{aligned}
& \Delta \pi_{i, U}(\mathcal{G}, \mathcal{A}) \geq \sum_{i k \in \mathcal{A}_{i, U}} \Delta \pi_{i, U}(\mathcal{G},\{i k\}), \\
& \Delta \pi_{j, D}(\mathcal{G}, \mathcal{A}) \geq \sum_{h j \in \mathcal{A}_{j, D}} \Delta \pi_{j, D}(\mathcal{G},\{h j\}) .
\end{aligned}
$$

A.LNEXT states that for any nonempty subset of agreements $\mathcal{A}$, there exists some agreement $i j \in \mathcal{A}$ such that the marginal contribution to $U_{i}$ (and $D_{j}$ ) of agreements $\mathcal{A}$ at $\mathcal{G}$ is weakly greater than the sum of the individual marginal contributions of all agreements in $\mathcal{A}$ that involve $U_{i}$ 
(and $D_{j}$ ) at $\mathcal{G}$. This is also equivalent to imposing a lower bound on the value to $U_{i}$ of agreements in $\mathcal{A}_{-i, U}$ (with a similar condition holding for some $D_{j}$ and agreements in $\mathcal{A}_{-j, D}$ ). We refer to the assumption as "limited negative externalities" since, when paired with A.SCDMC, this lower bound is weakly negative. ${ }^{25}$ Importantly, for each different subset of agreements $\mathcal{A}$, there can be a different pair $U_{i}$ and $D_{j}$ that satisfy this condition. We use A.LNEXT to help rule out equilibria with delay as it ensures that at any history of play, there is some pair of firms with an open agreement that would prefer all remaining open agreements to form. Given A.SCDMC, A.LNEXT is implied by Bloch and Jackson's (2007) nonnegative externalities condition.

Finally, we also restrict attention to equilibria that satisfy common tie breaking: at any history of play $h^{t}$, if there are two information sets in which any receiving firm has the same set of best responses, the firm chooses the same best response across both information sets. ${ }^{26}$ Similar types of restrictions - both informally and formally-have been used in the bargaining literature. ${ }^{27}$

We now state our second uniqueness result.

Theorem 4.2 (Uniqueness). Assume A.GFT, A.SCDMC, and A.LNEXT. For any $\Lambda>0$, every common tie-breaking equilibrium has the following properties: at every period $t$ and history $h^{t}$, all open agreements $i j \in \mathcal{C}\left(h^{t}\right)$ immediately form at prices $p_{i j, D}^{R}\left(p_{i j, U}^{R}\right)$ if $t$ is odd (even). As discussed in the previous section, when A.SCDMC is violated, there may exist no-delay equilibria in which prices are not Rubinstein but still arbi-

${ }^{25}$ To see why A.LNEXT and A.SCDMC admit weakly negative externalities, focus on the A.LNEXT condition for some $\mathcal{A}$ and firm $U_{i}, i j \in \mathcal{A}: \Delta \pi_{i, U}(\mathcal{G}, \mathcal{A}) \geq \sum_{i k \in \mathcal{A}_{i, U}} \Delta \pi_{i, U}(\mathcal{G},\{i k\})$. The left-hand side of this inequality can be expressed as

$$
\Delta \pi_{i, U}(\mathcal{G}, \mathcal{A})=\Delta \pi_{i, U}\left(\mathcal{G}, \mathcal{A}_{-i, U}\right)+\Delta \pi_{i, U}\left(\mathcal{G} \backslash \mathcal{A}_{-i, U}, \mathcal{A}_{i, U}\right)
$$

Substituting this expression into the A.LNEXT condition and rearranging terms yields

$$
\Delta \pi_{i, U}\left(\mathcal{G}, \mathcal{A}_{-i, U}\right) \geq \sum_{i k \in \mathcal{A}_{i, U}} \Delta \pi_{i, U}(\mathcal{G},\{i k\})-\Delta \pi_{i, U}\left(\mathcal{G} \backslash \mathcal{A}_{-i, U}, \mathcal{A}_{i, U}\right)
$$

Applying A.SCDMC, the right side of the inequality is less than or equal to zero. Thus, the marginal value of $\mathcal{A}_{-i, U}$ to $U_{i}$ at $\mathcal{G}$ needs to be greater than a value that is weakly negative for $U_{i}$ to satisfy the conditions of A.LNEXT.

${ }^{26}$ Common tie breaking is substantively different from restricting strategies to be Markovian or stationary. Markov strategies require that firms follow the same actions across different even or odd histories of play $h^{t}$ that share the same set of open agreements $\mathcal{C}\left(h^{t}\right)$. Common tie breaking does not require this, but rather restricts actions for receiving firms to be the same only for a given history of play $h^{t}$ across different sets of price offers that induce the same set of best responses.

${ }^{27}$ Ray and Vohra (2015) impose an equilibrium restriction that they call "compliance," which requires that a receiver of a bargaining proposal, when indifferent over a set of actions, chooses the action that is most preferred by the proposer (given equilibrium play). Brügemann et al. (2017) note that a related tie-breaking assumption, which they describe as "reasonable," is necessary to obtain uniqueness results under the Stole and Zwiebel (1996) union wage-bargaining model. 
trarily close to Nash-in-Nash prices as $\Lambda \rightarrow 0$ (as in theorem 3.4). It is an open research question whether, with weaker assumptions, all equilibria with complete (but not necessarily immediate) agreement have prices that are close to Nash-in-Nash prices as the time between periods becomes short.

We note that theorem 4.2 also holds under an alternative set of assumptions: instead of assuming A.LNEXT and restricting attention to common tie-breaking equilibria, it is sufficient to impose a "no-externality" assumption (formally defined in app. E) alongside A.SCDMC. This assumption still allows for interdependencies across agreements for a given firm but rules out externalities. We prove the statement of theorem 4.2 for both our main and alternative set of assumptions.

Overview of proof and role of assumptions. - The proof for theorem 4.2 proceeds by induction on the set of open agreements at any history of the game, $\mathcal{C}$. The proof establishes that if any subgame that begins with a strict subset of $\mathcal{C}$ agreements being open results in all open agreements forming immediately at Rubinstein prices (i.e., the inductive hypothesis), then any subgame beginning with $\mathcal{C}$ open agreements also must result in all open agreements forming immediately at Rubinstein prices (i.e., the inductive step). The base case follows from Rubinstein (1982), which establishes this result for any subgame with a single open agreement.

We start by proving the simultaneity of agreements - that is, in any equilibrium, if any open agreements are formed in period $t$, all open agreements are formed at $t$-when $\mathcal{C}$ contains agreements that involve multiple "receiving" firms (e.g., if $t$ is odd, there are multiple upstream firms with open agreements). Here, A.SCDMC allows us to rule out equilibria in which only a strict subset of open agreements are formed in a given period. To illustrate, consider a subgame in which there are $\mathcal{C}$ open agreements, and suppose that in an equilibrium, at least one agreement in $\mathcal{C}$ forms at period $t$, but not all agreements in $\mathcal{C}$ do. Consider some agreement $i j \in \mathcal{C}$ that does not form at $t$ and for which there exists another agreement that does form at $t$, where the receiving firm at $t$ differs from $i j$. We establish a contradiction by showing that the proposing firm involved in agreement $i j$ will find it profitable to make a deviant offer at $t$ that is slightly more generous than the Rubinstein price for this agreement. A.SCDMC ensures that the marginal value of forming this agreement to the receiving firm is weakly higher with open agreements than at $\mathcal{G}$, and hence the receiving firm will find it optimal to accept this offer. A.SCDMC further ensures that the proposing firm finds this deviation profitable even if the receiving firm were to change its set of acceptances upon receiving this deviant offer.

We next prove that when all open agreements are formed in a period in which there are multiple receiving firms, they are all formed at Rubinstein prices. We show that a receiving firm will reject an offer that is worse than 
the Rubinstein price by leveraging the fact that offers are simultaneous and that Rubinstein prices make a receiving firm indifferent between accepting and waiting (where, upon waiting, the agreement will then be formed at the Rubinstein price in the next period when only one open agreement remains). We show that a proposing firm will choose to adjust an offer that is worse for it than the Rubinstein price by showing that, if it were to adjust its offer slightly toward the Rubinstein price, this deviant offer would still be accepted by the receiving firm. Our restriction to common tie-breaking equilibria ensures that the receiving firm will not change its set of other acceptances upon accepting this deviant offer, thus ensuring that the deviation is profitable for the proposing firm.

We then prove the simultaneity of agreements at Rubinstein prices when open agreements are formed in a period in which there is only a single receiving firm with open agreements. With multiple receiving firms, we are able to leverage our inductive hypothesis to prove the previous results; with a single receiving firm, we can no longer always rely on induction: if the receiving firm rejects all offers in a given period, the set of open agreements will remain the same in the following period. To proceed, we employ arguments similar to those used in Shaked and Sutton (1984) to prove the uniqueness result in Rubinstein (1982). While the proof with a single receiving firm is more involved than with multiple receiving firms, the role of our assumptions is similar.

Finally, we prove that any equilibrium results in all open agreements being formed immediately. We leverage A.LNEXT to rule out delay, as it implies that, at any history, there is a pair of firms with an open agreement that benefits from all open agreements forming. ${ }^{28}$ Consequently, if there was not immediate agreement in a given period, there would be a profitable deviation for the proposer of this pair, whereby it would propose an offer to the receiver of this pair that would be accepted, resulting in the formation of all remaining open agreements by the next period at the latest (by the inductive hypothesis). As with our proof of simultaneity, A.SCDMC ensures that if the proposer in this pair makes the offer at a price that is slightly more generous than Rubinstein prices, then the receiver would accept this offer and the deviation would be profitable for the proposer. This rules out equilibria with delayed agreement and establishes our result.

To illustrate the possibility of an equilibrium with delay when A.LNEXT is violated, consider the following counterexample. Let there be two upstream firms, $U_{1}$ and $U_{2}$, and two downstream firms, $D_{1}$ and $D_{2}$, and let firms share a common discount factor $\delta$. Assume that $\mathcal{G}=\{11,22\}$, so that " 1 "

\footnotetext{
${ }^{28}$ Relatedly, Jehiel and Moldovanu (1995) show that the presence of negative externalities can potentially lead to delay in negotiations in a finite horizon sequential bargaining game.
} 
firms cannot form agreements with "2" firms. Suppose that the marginal value of agreement $\{11\}$ is 1 to both $U_{1}$ and $D_{1}$. However, suppose that the establishment of agreement $\{22\}$ imposes a negative externality of -10 on both $D_{1}$ and $U_{1}$. Let the "2" firms' payoffs be symmetric to these. Note that profits in this example satisfy A.GFT and A.SCDMC but not A.LNEXT (because of the large negative externalities imposed across pairs). There are (at least) two equilibria of this game. First, since this example satisfies the assumptions of theorem 3.2, one equilibrium involves the immediate formation of all agreements in $\mathcal{G}$ at Rubinstein prices. Second, another equilibrium has the four firms always proposing unattractive offers so that no agreements ever form in equilibrium. No pair has an incentive to "break" this second equilibrium because even though it knows that the marginal gain from its own agreement would be positive, the formation of this agreement would result in the other agreement forming in the following period and thereby impose a (present value) negative externality of $-10 \delta .^{29}$

\section{Relation of Our Model to the Applied Literature}

In this section, we discuss the connections between our model and applied papers that have, either directly or indirectly, appealed to the Nash-in-Nash solution concept. We first explain the key assumptions used in our analysis and their relation to the literature. We then detail the use of Nash-in-Nash in two strands of applied work. Our goal in this section is to inform the application of Nash-in-Nash and to highlight avenues for future research.

\section{A. Key Assumptions}

\section{Contract Space}

The applied literature has defined the Nash-in-Nash bargaining solution to be a set of bilateral contracts such that each contract is the solution to a bilateral Nash bargaining problem holding fixed the contracts of all other bilateral pairs. We make two key assumptions. First, contracts are over lump-sum transfer payments that are finalized upon agreement. Second, although profit functions depend on the set of agreements that has been formed, they do not depend on negotiated payments. Both restrictions hold in many models of wage negotiations between employers and workers (e.g., Horn and Wolinsky 1988b; Jun 1989; Westermark 2003) and in some applied papers in industrial organization settings (e.g., Noton and Elberg 2018).

${ }^{29}$ Note that the equilibria in this counterexample are similar to defection and cooperation equilibria of a repeated prisoner's dilemma game. 
Violations of these assumptions would significantly complicate our analysis: when profit functions are no longer a function of only the set of open agreements, strategies may also condition on additional information such as formed contract terms. ${ }^{30}$ Nevertheless, even in these more general settings, Nash-in-Nash solutions may still arise as an equilibrium outcome of a delegated agent model similar to the one provided in Section II.C. ${ }^{31}$

Many applied papers examine richer environments in which, for instance, firms agree on two-part or linear tariffs and then engage in further competition conditioning on these contracts (e.g., Draganska, Klapper, and Villas-Boas 2010; Crawford and Yurukoglu 2012). Our fundamental requirement is not specific to the contract space, per se, but rather the terms of negotiated contracts have no effect on profit functions and payments between firms are not affected by other actions. Thus, it may be possible to adapt our approach to richer settings. For example, Villas-Boas (2007) analyzes a model with two-part tariffs in which a single retailer negotiates with multiple upstream manufacturers. In their case, the firms may optimally set a linear fee equal to each upstream firm's (constant) marginal costs; bargaining would then be essentially only over lump-sum payments, and manufacturer profits would not depend on the agreements formed by others. ${ }^{32}$

Even with lump-sum transfers, payments may not be finalized once agreements are formed. This may occur if contracts are renegotiated upon disagreement (e.g., Stole and Zwiebel 1996; Navarro and Perea 2013; Brügemann et al. 2017), are contingent on the set of agreements that has been formed (e.g., Inderst and Wey 2003; de Fontenay and Gans 2014), or have exogenously determined contingencies due to, for example, bankruptcy (e.g., Raskovich 2003). Different results may emerge in these cases. For example, consider again the automobile parts supplier example with three suppliers from Section III.A, which violates A.FEAS and hence for which a Nash-in-Nash limit equilibrium of our alternating offers game does not exist. Now modify the example so that the manufacturer pays suppliers only if all three agreements have been formed. ${ }^{33}$ In this case, the solution coincides with the nucleolus of an associated game (Montez 2014): each

\footnotetext{
${ }^{30}$ Extending the analysis would also raise issues similar to those studied in the vertical contracting literature on opportunism (Hart and Tirole 1990; McAfee and Schwartz 1994; Rey and Vergé 2004).

${ }^{31}$ The literature on two-party alternating offers bargaining games has been extended to richer contract spaces (Binmore et al. 1986; Herrero 1989). In such contract spaces, if delegated agents believe that all other bilateral agreements will immediately form with contracts that converge to the Nash-in-Nash solution, then their own agreements can be shown under certain conditions to also converge to the Nash-in-Nash solution.

${ }^{32}$ A similar insight holds when linear fees are negotiated alongside fixed quantities (e.g., as in Beckert, Smith, and Takahashi [2015]).

${ }^{33}$ This can occur if the manufacturer is able to declare bankruptcy as in Raskovich (2003) or if linear fees are negotiated and a manufacturer engages in production only if all three agreements are formed.
} 
supplier is paid 1/4 (a viable outcome with production) as opposed to $1 / 2$ in our original example.

Ultimately, characterizing outcomes in bilateral oligopoly with more general contract spaces remains an open research agenda. We view our current analysis as a step toward understanding the applicability of Nash-in-Nash in such environments.

\section{Network of Potential Agreements}

In applied work, the Nash-in-Nash solution has typically conditioned on the set of agreements that is formed and focused on negotiated contracts given those agreements. Mirroring this practice, we have assumed that the set of agreements allowed to form, $\mathcal{G}$, is exogenous and that all agreements in this set create bilateral gains from trade (A.GFT), thereby motivating our focus on equilibria in which all agreements in $\mathcal{G}$ form. Our paper thus focuses on surplus division for a given set of agreements and does not provide an analysis of which network of agreements forms.

As noted in Lee and Fong (2013), the equilibrium set of agreements that forms and the division of surplus for those agreements may be intertwined. For example, potential agreements that are not formed in equilibrium can be used as threats to improve bargaining outcomes. ${ }^{34}$ Approaches that combine insights from the bargaining literature with those from the network formation literature with transfers (cf. Jackson 2004; Bloch and Jackson 2007) are promising avenues for future research.

\section{Profit Assumptions}

Our results rely on several assumptions on firm profits. First, all our results rely on A.GFT. In most applied settings, this assumption is often explicitly or implicitly maintained: it is unreasonable to expect that firms form bilateral agreements in equilibrium when doing so reduces their bilateral surplus.

We next focus on A.WCDMC, which (together with A.GFT) ensures the existence of a Nash-in-Nash limit equilibrium. A.WCDMC restricts the marginal contribution of any set of agreements to be weakly greater than the sum of the marginal contribution of each individual agreement within the set. An important setting in which A.WCDMC is satisfied is one in which a single downstream firm negotiates with multiple upstream suppliers that are (imperfect) substitutes for one another, as the marginal contribution of any given supplier to the downstream firm is decreasing as the downstream firm forms additional agreements. This setting is common to applied the-

\footnotetext{
${ }^{34}$ For instance, a number of recent working papers including Ghili (2016), Liebman (2016), and Ho and Lee (2019) examine selective contracting by health insurance firms and hospitals and allow for firms to use potential agreements not contained in $\mathcal{G}$ as threats.
} 
ory papers that examine the impact of downstream "buyer power" on negotiated prices, upstream supplier incentives, and welfare (e.g., Chipty and Snyder 1999; Inderst and Wey 2007; Inderst and Valletti 2011; O'Brien 2014; Chen 2019) and in certain empirical work in health care markets (e.g., Capps et al. 2003; Grennan 2013; Gowrisankaran et al. 2015). ${ }^{35}$

We have also shown that A.FEAS holding on one side of the market and A.SCDMC holding on the other side ensures the existence of a Nash-inNash limit equilibrium. These assumptions hold in Easterbrook et al. (2019), which examines the impact of mergers of upstream firms providing complementary products.

Finally, we have shown that A.SCDMC and A.LNEXT together ensure that the Nash-in-Nash solution is the unique equilibrium outcome. In more general settings, particularly with multiple upstream and downstream firms, these assumptions may be difficult to verify. However, these assumptions will be satisfied in settings in which a single downstream firm negotiates with multiple upstream firms that are substitutes and in which upstream firm profits do not depend on the set of agreements that has been formed. Many of the buyer power, wage bargaining, and health care market papers noted above satisfy these assumptions. In addition, Möllers, Normann, and Snyder (2017) explicitly verify that A.SCDMC and A.LNEXT hold in their application.

\section{B. Examples in Applied Literature}

We now detail the use of Nash-in-Nash bargaining in two applied literatures and describe how our results can provide a foundation for this solution concept in certain settings. In doing so, we show how one might verify when applied papers satisfy our assumptions.

First, Chipty and Snyder (1999) and a subsequent literature examine negotiations between a monopolist content supplier negotiating with multiple downstream cable distributors. Such an environment has also been studied in other papers (e.g., Crawford and Yurukoglu 2012; Crawford et al. 2018) and shares similarities to other content distribution and hardware-software industries (e.g., Lee 2013). In Chipty and Snyder's study, downstream distributors are local monopolists that do not compete with one another, and negotiations are over both a quantity provided and a tariff. In their implementation of the Nash-in-Nash solution, they assume that bilateral negotiations between the supplier and each distributor maximize joint surplus

\footnotetext{
${ }^{35}$ Some of these papers employ contract spaces different from ours. As noted above, when contracts represent richer objects than lump-sum transfers, it will often be the case that profits depend on both the set of agreements that has been formed and the terms of contracts that have been signed. In such cases, our profit assumptions can be evaluated with respect to a given set of contracts.
} 
(resulting in the bilaterally efficient quantity being supplied) and use a lump-sum payment to equally split the bilateral gains from trade (computed under the assumption that the efficient quantities supplied to other distributors are fixed). Given the existence of bilateral gains from trade between the supplier and each distributor, if the supplier's profit function is concave in the quantity supplied, then A.SCDMC and A.LNEXT hold. ${ }^{36}$ Furthermore, as long as the supplier's profit function is not too convex, A.FEAS holds for the supplier (and A.SCDMC continues to hold for the distributors). Thus, under functional form assumptions regarding payoffs and the assumption that the quantities supplied are fixed at efficient levels, their solution is supportable as an equilibrium (and in certain cases the unique equilibrium) outcome of our noncooperative extensive form.

Second, Capps et al. (2003), together with Town and Vistnes (2001), provide an "option demand market" foundation for much of the recent applied literature on insurer-provider negotiations in health care markets (e.g., Ho 2009; Gowrisankaran et al. 2015; Ho and Lee 2017). Although Capps et al. do not explicitly apply the Nash-in-Nash bargaining framework, they note that their reduced-form bargaining solution coincides with the cooperative, complete information Nash bargaining solution. Capps et al. employ two key assumptions. First, the objective that an insurer maximizes is proportional to the consumer welfare generated from its hospital network. Together with their demand system, this assumption implies that A.SCDMC holds for each insurer. ${ }^{37}$ Second, each hospital's total payoffs are a fixed proportion of the incremental gains that it generates to an insurer, which is consistent with hospitals being reimbursed at marginal costs and then bargaining over a lump-sum payment. These assumptions together imply that A.SCDMC and A.LNEXT hold. Consequently, the solution concept relied on in Capps et al.'s paper also emerges as the unique equilibrium outcome of our noncooperative extensive form.

\footnotetext{
${ }^{36}$ As Chipty and Snyder note, if the upstream firm's profit function is given by $V(Q) \equiv R(Q)-C(Q)$, where $Q$ is the total quantity that it supplies and $R(\cdot)$ and $C(\cdot)$ are revenue and cost functions, this condition holds if the supplier's revenue function is concave and the cost function is convex.

${ }^{37}$ Capps et al. (2003) assume that each insurer maximizes ex ante enrollee surplus. The surplus generated by a network $\mathcal{H}$ of hospitals can be expressed as $\Sigma_{i} \log \left(\sum_{j \in \mathcal{H}} u_{i j}\right)$, where $u_{i j}$ is the exponentiated utility (net of an independently and identically distributed type I extreme value error) that patient $i$ receives from visiting hospital $j$ and the $i$ sum is over enrollees. The marginal contribution of some hospital $k \notin \mathcal{H}$ to the insurer's network-referred to as "willingness to pay," or WTP_can be expressed as
}

$$
\mathrm{WTP}=\sum_{i} \log \left(u_{i k}+\sum_{j \in \mathcal{H}} u_{i j}\right)-\sum_{i} \log \left(\sum_{j \in \mathcal{H}} u_{i j}\right) .
$$

This term is decreasing as elements are added to $\mathcal{H}$, a property that holds more generally in random coefficients logit models (e.g., Berry, Levinsohn, and Pakes 1995). 


\section{Concluding Remarks}

In this paper, we have provided a bargaining model that extends the Rubinstein (1982) alternating offers game to bilateral oligopoly. We establish two sets of results. Our first set of results proves that a Nash-in-Nash limit equilibrium exists if (i) there are gains from trade, (ii) a feasibility condition holds, and (iii) either a weak declining contribution condition holds or a stronger declining contribution holds for one side of the market only. We also show that the feasibility condition is necessary for a Nash-in-Nash limit equilibrium to exist. Our second set of results proves that the Nashin-Nash outcome is unique for any no-delay equilibrium. Under stronger conditions on profits, it is also unique for any common tie-breaking equilibrium.

Our results provide support for the Nash-in-Nash solution as a credible bargaining framework for use in certain areas of applied work. In addition to our assumptions on profits, we restrict the contract space (i.e., lump-sum payments that do not affect firm profits and are finalized upon agreement) and require a fixed network of potential agreements. We believe that these assumptions and our extensive form - which allows firms to coordinate across multiple negotiations unlike the prior literature that used delegated agents - reasonably capture aspects of firm competition and bargaining protocols in particular real-world industry settings. Moreover, our analysis may serve as a useful framework to better understand conditions under which this solution might emerge in other environments and settings, such as with richer contract spaces.

\section{References}

Beckert, Walter, Howard Smith, and Yuya Takahashi. 2015. "Competitive Price Discrimination in a Spatially Differentiated Intermediate Goods Market." Technical report, Univ. London.

Berry, Steve, James Levinsohn, and Ariel Pakes. 1995. "Automobile Prices in Market Equilibrium." Econometrica 63 (4): 841-90.

Binmore, Ken. 1987. "Nash Bargaining Theory (II)." In The Economics of Bargaining, edited by Ken Binmore and Partha Dasgupta. Cambridge: Blackwell.

Binmore, Ken, Ariel Rubinstein, and Asher Wolinsky. 1986. "The Nash Bargaining Solution in Economic Modelling." RAND I. Econ. 17 (2): 176-88.

Björnerstedt, Jonas, and Johan Stennek. 2007. "Bilateral Oligopoly-the Efficiency of Intermediate Goods Markets." Internat. I. Indus. Org. 25 (5): 884-907.

Bloch, Francis, and Matthew O. Jackson. 2007. "The Formation of Networks with Transfers among Players.” I. Econ. Theory 133 (1): 83-110.

Brügemann, Björn, Pieter Gautier, and Guido Menzio. 2017. "Intra Firm Bargaining and Shapley Values." Working Paper no. 21508, NBER, Cambridge, MA.

Capps, Cory, David Dranove, and Mark Satterthwaite. 2003. "Competition and Market Power in Option Demand Markets.” RAND I. Econ. 34 (4): 737-63.

Chae, S., and J. Yang. 1994. "An N-Person Pure Bargaining Game.” L. Econ. Theor 62 (1): 86-102. 
Chatterjee, Kalyan, Bhaskar Dutta, Debraj Ray, and Kunal Sengupta. 1993. "A Noncooperative Theory of Coalitional Bargaining." Rev. Econ. Studies 60 (2): 46377.

Chen, Zhiqi. 2019. "Supplier Innovation in the Presence of Buyer Power." Internat. Econ. Rev. 60 (1).

Chipty, Tasneem, and Christopher M. Snyder. 1999. "The Role of Firm Size in Bilateral Bargaining: A Study of the Cable Television Industry." Rev. Econ. and Statis. 81 (2): 326-40.

Corominas-Bosch, Margarida. 2004. "Bargaining in a Network of Buyers and Sellers." L. Econ. Theory 115 (1): 35-77.

Crawford, Gregory S., Robin S. Lee, Michael D. Whinston, and Ali Yurukoglu. 2018. "The Welfare Effects of Vertical Integration in Multichannel Television Markets." Econometrica 86 (3): 891-954.

Crawford, Gregory S., and Ali Yurukoglu. 2012. "The Welfare Effects of Bundling in Multichannel Television Markets.” A.E.R. 102 (2): 643-85.

Cremer, Jacques, and Michael H. Riordan. 1987. "On Governing Multilateral Transactions with Bilateral Contracts." RAND I. Econ. 18 (3): 436-51.

Davidson, Carl. 1988. "Multiunit Bargaining in Oligopolistic Industries." L. Labor Econ. 6 (3): 397-422.

de Fontenay, Catherine C., and Joshua S. Gans. 2005. "Vertical Integration in the Presence of Upstream Competition." RAND J. Econ. 36 (3): 544-72. $756-88$.

Dobson, Paul W. 1994. "Multifirm Unions and the Incentive to Adopt Pattern Bargaining in Oligopoly." European Econ. Rev. 38:87-100.

Dobson, Paul W., and Michael Waterson. 2007. "The Competition Effects of Industry-Wide Vertical Price Fixing in Bilateral Oligopoly." Internat. I. Indus. Org. 25:935-62.

Draganska, Michaela, Daniel Klapper, and Sofia B. Villas-Boas. 2010. “A Larger Slice or a Larger Pie? An Empirical Investigation of Bargaining Power in the Distribution Channel." Marketing Sci. 29 (1): 57-74.

Easterbrook, Kathleen F., Gautam Gowrisankaran, Dina Older Aguilar, and Yufei Wu. 2019. "Accounting for Complementarities in Hospital Mergers: Is a Substitute Needed for Current Approaches?” Antitrust Law J. 82 (2).

Elliott, Matthew. 2015. "Inefficiencies in Networked Markets." American Econ. I.: Microeconomics 7 (4): 43-82.

Farrell, Joseph, David J. Balan, Keith Brand, and Brett W. Wendling. 2011. "Economics at the FTC: Hospital Mergers, Authorized Generic Drugs, and Consumer Credit Markets." Rev. Indus. Org. 39:271-96.

Ghili, Soheil. 2016. "Network Formation and Bargaining in Vertical Markets: The Case of Narrow Networks in Health Insurance.” Technical report, Northwestern Univ.

Gomes, Armando. 2005. "Multilateral Contracting with Externalities." Econometrica 73 (4): 1329-50.

Gowrisankaran, Gautam, Aviv Nevo, and Robert Town. 2015. "Mergers When Prices Are Negotiated: Evidence from the Hospital Industry." A.E.R. 105 (1): 172-203.

Grennan, Matthew. 2013. "Price Discrimination and Bargaining: Empirical Evidence from Medical Devices." A.E.R. 103 (1): 147-77.

Hart, Oliver, and Jean Tirole. 1990. "Vertical Integration and Market Foreclosure." Brookings Papers Econ. Activitv: Microeconomics, 205-86.

Hellmann, Tim. 2013. "On the Existence and Uniqueness of Pairwise Stable Networks." Internat. I. Game Theory 42 (1): 211-37. 
Herrero, Maria Jose. 1989. "The Nash Program: Non-convex Bargaining Problems." L. Econ. Theory 49 (2): 266-77.

Ho, Katherine. 2009. "Insurer-Provider Networks in the Medical Care Market." A.E.R. 99 (1): 393-430.

Ho, Katherine, and Robin S. Lee. 2017. "Insurer Competition in Health Care Markets." Econometrica 85 (2): 379-417.

. 2019. "Equilibrium Provider Networks: Bargaining and Exclusion in Health Care Markets." A.E.R. 109 (2).

Horn, Henrick, and Asher Wolinsky. 1988a. "Bilateral Monopolies and Incentives for Merger." RAND I. Econ. 19 (3): 408-19.

. 1988b. "Worker Substitutability and Patterns of Unionisation." Econ. I. 98:484-97.

Inderst, Roman, and Joao Montez. Forthcoming. "Buyer Power and Dependency in a Model of Negotiations." RAND J. Econ.

Inderst, Roman, and Tommaso M. Valletti. 2011. "Buyer Power and the 'Waterbed Effect.'" L. Indus. Econ. 54 (1): 1-20.

Inderst, Roman, and Christian Wey. 2003. "Bargaining, Mergers, and Technology Choice in Bilaterally Oligopolistic Industries." RAND I. Econ. 34 (1): 1-19.

. 2007. "Buyer Power and Supplier Incentives." European Econ. Rev. 51 (3): $647-67$.

Iozzi, Alberto, and Tommaso Valletti. 2014. "Vertical Bargaining and Countervailing Power." American Econ. I.: Microeconomics 6 (3): 106-35.

Jackson, Matthew O. 2004. "A Survey of Models of Network Formation: Stability and Efficiency." In Group Formation in Economics: Networks, Clubs and Coalitions, edited by Gabrielle Demange and Myrna Wooders, chap. 1. Cambridge: Cambridge Univ. Press.

Jehiel, Philippe, and Benny Moldovanu. 1995. "Negative Externalities May Cause Delay in Negotiation." Econometrica 63 (6): 1321-35.

Jun, Byoung Heon. 1989. "Non-cooperative Bargaining and Union Formation." Rev. Econ. Studies 56 (1): 59-76.

Kranton, Rachel E., and Deborah F. Minehart. 2001. "A Theory of Buyer-Seller Networks." A.E.R. 91 (3): 485-508.

Krishna, Vijay, and Roberto Serrano. 1996. "Multilateral Bargaining." Rev. Econ. Studies 63 (1): 61-80.

Lee, Robin S. 2013. "Vertical Integration and Exclusivity in Platform and TwoSided Markets." A.E.R. 103 (7): 2960-3000.

Lee, Robin S., and Kyna Fong. 2013. "Markov Perfect Network Formation: An Applied Framework for Bilateral Oligopoly and Bargaining in Buyer-Seller Networks." Discussion paper, Harvard Univ.

Liebman, Eli. 2016. "Bargaining in Markets with Exclusion: An Analysis of Health Insurance Networks." Technical report, Duke Univ.

Manea, Mihai. 2011. "Bargaining in Stationary Networks." A.E.R. 101 (5): 2042 80 .

McAfee, R. Preston, and Marius Schwartz. 1994. "Opportunism in Multilateral Vertical Contracting: Nondiscrimination, Exclusivity, and Uniformity.” A.E.R. 84 (1): 210-30.

Merlo, Antonio, and Charles Wilson. 1995. "A Stochastic Model of Sequential Bargaining with Complete Information.” Econometrica 63 (2): 371-99.

Möllers, Claudia, Hans-Theo Normann, and Christopher M. Snyder. 2017. "Communication in Vertical Markets: Experimental Evidence." Internat. I. Indus. Org. 50 (1): 214-58. 
Montez, João. 2014. "One-to-Many Bargainings When Pairwise Agreements Are Non-renegotiable." I. Econ. Theory 152:249-65.

Muthoo, Abhinay. 1999. Bargaining Theory with Applications. Cambridge: Cambridge Univ. Press.

Nash, J. F. 1950. "The Bargaining Problem.” Econometrica 18 (2): 155-62.

Navarro, Noemí, and Andres Perea. 2013. "A Simple Bargaining Procedure for the Myerson Value.” B.E. I. Theoretical Econ. 13 (1): 20.

Noton, Carlos, and Andrés Elberg. 2018. "Are Supermarkets Squeezing Small Suppliers? Evidence from Negotiated Wholesale Prices." Econ._. 128 (610): 1304-30.

O'Brien, Daniel P. 2014. "The Welfare Effects of Third-Degree Price Discrimination in Intermediate Good Markets: The Case of Bargaining." RAND I. Econ. 45 (1): $92-115$.

O’Brien, Daniel P., and Greg Shaffer. 1992. "Vertical Control with Bilateral Contracts." RAND I. Econ. 23:299-308.

Polanski, Arnold. 2007. "Bilateral Bargaining in Networks." L.Econ. Theory 134 (1): 557-65.

Raskovich, Alexander. 2003. "Pivotal Buyers and Bargaining Position." L. Indus. Econ. 51 (4): 405-26.

Ray, Debraj, and Rajiv Vohra. 2015. "Coalition Formation." In Handbook of Game Theory with Economic Applications, vol. 4, edited by H. Peyton Young and Shmuel Zamir, chap. 5. Amsterdam: Elsevier.

Rey, Patrick, and Thibaud Vergé. 2004. "Bilateral Control with Vertical Contracts." RAND I. Econ. 35 (4): 728-46.

Rogerson, William P. 2014. "A Vertical Merger in the Video Programming and Distribution Industry: Comcast-NBCU (2011).” In The Antitrust Revolution: Economics, Competition, and Policy, 6th ed., edited by John E. Kwoka and Lawrence J. White. Oxford: Oxford Univ. Press.

Rubinstein, Ariel. 1982. "Perfect Equilibrium in a Bargaining Model." Econometrica 50 (1): 97-109.

Segal, Ilya. 1999. "Contracting with Externalities." O.J.E. 114 (2): 337-88.

Serrano, Roberto. 2005. "Fifty Years of the Nash Program, 1953-2003." Investigaciones Económicas 24 (2): 219-58.

Shaked, Avner, and John Sutton. 1984. "Involuntary Unemployment as a Perfect Equilibrium in a Bargaining Model." Econometrica 52 (6): 1351-64.

Stole, Lars A., and Jeffrey Zwiebel. 1996. "Intra-firm Bargaining under Nonbinding Contracts." Rev. Econ. Studies 63 (3): 375-410.

Town, Robert J., and Gregory Vistnes. 2001. "Hospital Competition in HMO Networks." I. Health Econ. 20:733-53.

Villas-Boas, Sofia B. 2007. "Vertical Relationships between Manufacturers and Retailers: Inference with Limited Data." Rev. Econ. Studies 74 (2): 625-52.

Westermark, Andreas. 2003. "Bargaining, Binding Contracts, and Competitive Wages." Games and Econ. Behavior 43 (2): 296-311.

Whinston, Michael D. 2006. Lectures on Antitrust Economics. Cambridge, MA: MIT Press. 